\title{
Effect of Different Concentrations of Taurine on Certain Biochemical Parameters During Cryopreservation of Gir Bull Semen
}

\author{
P.S. Chikhaliya ${ }^{1}$, A.R. Ahlawat ${ }^{1}$, V.K. $\operatorname{Singh}^{1}$, H.P. Vijyeta ${ }^{2}$, \\ M.D. Odedra ${ }^{1}$ and K.B. Vala ${ }^{1}$ \\ ${ }^{1}$ College of Veterinary Science \& A.H., Junagadh Agricultural University, Junagadh, India \\ ${ }^{2}$ Cattle Breeding Farm, Junagadh Agricultural University, Junagadh, India \\ *Corresponding author
}

\begin{tabular}{l} 
Ke y w o r d s \\
$\begin{array}{l}\text { Gir bull, Semen, } \\
\text { taurine, Glutathione } \\
\text { reductase, Lipid } \\
\text { peroxidation }\end{array}$ \\
Article Info \\
$\begin{array}{l}\text { Accepted: } \\
\text { 10 June } 2018 \\
\text { Available Online: } \\
\text { 10 July } 2018\end{array}$ \\
\hline
\end{tabular}

A Total 8 semen sample from four healthy Gir breeding bulls were collected at weekly interval for two weeks period using of artificial vagina method for evaluation of semen biochemical attributes at various stages of cryopreservation of Gir bull semen. The overall mean values for oxidative stress parameters viz. lipid peroxidation and glutathione reductase were $51.14 \pm 0.18 \mu \mathrm{mol} / \mathrm{ml}$ and $32.24 \pm 0.64 \mathrm{U} / \mathrm{L}$, respectively in neat semen samples. The difference was non-significant among the bulls for the glutathione reductase, while significant $(\mathrm{P}<0.05)$ difference was found for the lipid peroxidation. Mean Malondialdehyde (MDA) level were $30.74 \pm 0.55 \mu \mathrm{mol} / \mathrm{ml}$ in $50 \mathrm{mM}$ Taurine group at postthaw stages of cryopreservation, and were significantly $(\mathrm{P}<0.05)$ lower as compared to that of the other groups. Mean glutathione reductase levels in $50 \mathrm{mM}$ Taurine group were $64.76 \pm 0.78 \mathrm{U} / \mathrm{L}$ at pre-freeze stages of cryopreservation, and were significantly $(\mathrm{P}<0.05)$ higher as compared to that of the other groups. Mean Malondialdehyde (MDA) level was $15.95 \pm 0.74 \mu \mathrm{mol} / \mathrm{ml}$ in $50 \mathrm{mM}$ Taurine group at post-thaw stages of cryopreservation, and were significantly $(\mathrm{P}<0.05)$ lower as compared to that of the other groups. Mean glutathione reductase levels in $50 \mathrm{mM}$ Taurine group were $80.25 \pm 4.85 \mathrm{U} / \mathrm{L}$ at post-thaw stages of cryopreservation, and were significantly $(\mathrm{P}<0.05)$ higher as compared to that of the other groups.

\section{Introduction}

Gir is well known milch breed of Indian. It well known for its milk production, docility and emotional temperament. This breed is found in and around districts like Junagadh, Amreli, Bhavnagar, Gir Somnath, Rajkot, Porbandar and some parts of Jamnagar, Morabi, Surendranagar district of Saurashtra. This breed is also locally known as Bhodali,
Kathiyawari, and Sorathi. Pure Gir heard is well maintained at Cattle Breeding Farm Junagadh, JAU.

One of the most important factors contributing to poor quality semen has been reported to be oxidative stress (Bucak et al., 2010). Oxidative stress is a condition associated with an increased rate of cellular damage induced by oxygen and oxygen derived oxidants 
commonly known as ROS (Sikka et al., 1995). Gametes are susceptible to reactive oxygen species (ROS) attack. When manipulated in vitro during assisted reproductive techniques, these cells run the risk of generating and being exposed to supra-physiological level of ROS (Du Plessis et al., 2008). Among various causes, oxidative stress (OS) has been attributed to affect the fertility status and physiology of spermatozoa (Agarwal et al., 2008).

Moreover, bovine spermatozoa are prone to membrane damage due to high content of polyunsaturated fatty acids in the sperm membrane and lack of a significant antioxidant system in the cytoplasm (Bailey et al., 2000). This makes bovine spermatozoa particularly susceptible to Lipid Peroxidation (LPO) in presence of ROS (Sinha et al., 1996).

Bansal and Bilaspuri, (2011) reviewed the impact of oxidative stress and antioxidants on sperm function and explained effects of various types of antioxidants. The effects of LPO include irreversible loss in motility, damage to the sperm DNA, and decreased fertility (Perumal et al., 2011 and Maxwell and Watson, 1996). In recent years, studies have also been conducted on bovine semen diluents, including additives such as, taurine, trehalose, selenium, GSH, GPX, CAT, SOD, and surfactant compounds, so as to improve motility, viability, and membrane integrity of spermatozoa (Aisen et al., 2002 and Uysal et al., 2005).

The addition of antioxidants such as taurine to ovine sperm (Bucak and Tekin, 2007), feline sperm (Baran et al., 2009), and rabbit sperm (Alvarez et al., 1987) has been shown to protect sperm against the harmful effects of ROS and improve sperm motility and membrane integrity during sperm liquid storage.
Keeping in mind the above factors a study was planned to study the effect of different concentrations of taurine as an additive in and romed extender during the cryopreservation of Gir bull semen

\section{Materials and Methods}

A total of four Gir bulls aged between 4 to 6 years of Cattle Breeding Farm, Junagadh were used for the study. All bulls included in study had sound general reproductive health and were maintained under uniform managemental conditions

The semen was collected at homosexual mount by Artificial Vagina (Danish model) once a week. A total of 8 ejaculates, 4 from each bull were collected for assessment and preservation. Immediately after collection, semen collection tubes were placed in water bath at $35^{\circ} \mathrm{C}$. The collected semen was examined microscopically and all routine seminal traits were recorded. After initial dilution and evaluation of semen ejaculates with more than 70 per cent initial progressive motility, were divided in four equal aliquots. Subsequently, Aliquot-1 was diluted with 25 $\mathrm{mM}$ Taurine (25 mM Taurine group), Aliquot2 was diluted with $50 \mathrm{mM}$ Taurine $(50 \mathrm{mM}$ Taurine group), Aliquot-3 was diluted with 75 $\mathrm{mM}$ Taurine (75 $\mathrm{mM}$ Taurine group) and Aliquot-4 was kept without any additive which was served as control. The dilution rate was calculated automatically by the photometer (Accucel, IMV, France) against 530nM wavelength After dilution, each semen aliquots were filled and sealed in French Medium transparent Straw $(0.5 \mathrm{ml}$ capacity, TBS ${ }^{\mathrm{TM}}$, IMV, France) by Automatic Filling and Sealing Machine (MRS1 Dual, IMV, France) and printed using straw printer (IMV, France). Straws were then arranged in Freezing Rack and were transferred to Cold Handling Cabinet (Macro scientific Pvt. Ltd, New Delhi.) already maintained at $4^{0} \mathrm{C}$ kept 
for 4 hours of equilibration period. Then after straws were vapour freezed using conventional method and then all the straws were submerged in Liquid Nitrogen at $-196^{\circ} \mathrm{C}$ for storage. After cryopreservation, straws were thawed at $37^{\circ} \mathrm{C}$ for 30 seconds in a water bath to evaluate post-thaw individual motility, sperm viability, sperm abnormality, plasma membrane integrity (HOST) and acrosomal integrity. The seminal plasma was collect from neat semen and cryopreserved semen straws at pre-freeze and post-thaw stages by centrifuging at $3000 \mathrm{rpm}$ for 10 minutes and evaluated for biochemical attribute like MDA and GR by using standard kit provided by sigma Aldrich (Saint Louis, USA)

\section{Results and Discussion}

\section{Biochemical parameter values for neat Gir bull semen}

\section{Lipid peroxidation (LPO)}

The overall mean Malondialdehyde (MDA) values of semen samples was $51.14 \pm 0.18$ $\mu \mathrm{mol} / \mathrm{ml}$ with a range of 50 to $52 \mu \mathrm{mol} / \mathrm{ml}$. The mean values of Malondialdehyde (MDA) were $50.5 \pm 0.03,51.4 \pm 0.02,51.51 \pm 0.13$ and $50.3 \pm 0.01$ for the Pankaj, Pratap, Sarang and Vasu bulls, respectively. The mean Malondialdehyde (MDA) differed significantly among the bulls (Table 1). Similar findings were reported by Shaikh (2014) in Kankeraj breeds of cattle.

\section{Glutathione reductase (GR)}

The overall mean glutathione reductase (GR) of semen was $32.24 \pm 0.64 \mathrm{U} / \mathrm{L}$ with a range of 31.16 to $36.12 \mathrm{U} / \mathrm{L}$. The mean values of glutathione reductase were $33.51 \pm 2.91,31.50$ $\pm 0.25,32.62 \pm 0.02$ and $31.31 \pm 0.015 \mathrm{U} / \mathrm{L}$ for the Pankaj, Pratap, Sarang and Vasu bulls, respectively (Table 1). Value observed for Gluthathione reductase in the present study is in agreement with the reports of the Shaikh (2014) in Kankrej bulls who has reported the GR level as $30.14 \pm 0.06 \mathrm{U} / \mathrm{L}$.

Effect of taurine as a semen additive during cryopreservation on biochemical parameter of Gir bull semen

\section{Lipid peroxidation (LPO)}

The mean Malondialdehyde (MDA) values in pre freeze stage and post thaw stage were $36.33 \pm 0.76$ and $24.53 \pm 0.63 \mu \mathrm{mol} / \mathrm{ml}$ in $25 \mathrm{mM}$ Taurine group; $30.74 \pm 0.55$ and 15.95 $\pm 0.74 \mu \mathrm{mol} / \mathrm{ml}$ in $50 \mathrm{mM}$ Taurine group; 37.6 \pm 0.63 , and $28.48 \pm 0.55 \mu \mathrm{mol} / \mathrm{ml}$ in $75 \mathrm{mM}$ Taurine group and $38.57 \pm 0.70$ and $28.07 \pm$ $1.26 \mu \mathrm{mol} / \mathrm{ml}$ in control group at pre-freeze and post-thaw stages of cryopreservation, respectively. The mean Malondialdehyde (MDA) value in $50 \mathrm{mM}$ Taurine group was significantly $(\mathrm{P}<0.05)$ lower at pre-freeze and post-thaw stages of cryopreservation as compared to that of the $25 \mathrm{mM}$ Taurine, 75 $\mathrm{mM}$ Taurine and control groups. It was also observed that Malondialdehyde (MDA) values was found to be significantly $(\mathrm{P}<0.05)$ higher in all groups at pre-freeze stage as compared to post-thaw stage of cryopreservation in the present study (Table 2).

These findings are in accordance with (Chhillar et al., 2012) who also have reported that the addition of 50mMTaurine to the freezing extender resulted in significantly decreased Malondialdehyde (MDA) at postthaw stage in Karan-Fries bulls.

Similarly, Serpil et al., (2009) have also reported a significantly lower Malondialdehyde (MDA) at post-thaw stage but at lower concentration of Taurine in cattle bull. Whereas, Atessahin et al., (2008) have reported a significantly lower Malondialdehyde (MDA) at post-thaw stage but using higher concentration $(75 \mathrm{mM})$ of 
Taurine in Angora Goat. Perumal et al., Taurine concentration but for the liquid (2013) have also found significantly lowered storage of mithun bull semen.

Malondialdehyde (MDA) level at $50 \mathrm{mM}$

Table.1 Biochemical parameters of neat semen of Gir bulls (Mean \pm SE)

\begin{tabular}{|l|c|c|}
\hline \multirow{2}{*}{$\begin{array}{l}\text { Bull Name } \\
(\mathbf{n}=\mathbf{4})\end{array}$} & \multicolumn{2}{|c|}{ Oxidative stress parameters } \\
\cline { 2 - 3 } & $\begin{array}{c}\text { Lipid Peroxidation } \\
(\boldsymbol{\mu m o l} / \mathbf{m l})\end{array}$ & $\begin{array}{c}\text { Glutathione Reductase } \\
(\mathbf{U} / \mathbf{L})\end{array}$ \\
\hline Pankaj $(\mathbf{n = 2})$ & $50.50 \pm 0.03^{\mathrm{a}}$ & $33.51 \pm 2.91^{\mathrm{a}}$ \\
\hline Pratap $(\mathbf{n}=\mathbf{2})$ & $51.40 \pm 0.02^{\mathrm{ab}}$ & $31.50 \pm 0.25^{\mathrm{a}}$ \\
\hline Sarang $(\mathbf{n = 2})$ & $51.51 \pm 0.13^{\mathrm{b}}$ & $32.62 \pm 0.02^{\mathrm{a}}$ \\
\hline Vasu $(\mathbf{n = 2})$ & $50.30 \pm 0.01^{\mathrm{ab}}$ & $31.31 \pm 0.01^{\mathrm{a}}$ \\
\hline Overall $(\mathbf{n}=\mathbf{8})$ & $51.14 \pm 0.18$ & $32.24 \pm 0.64$ \\
\hline
\end{tabular}

Means with different superscripts within column and mean with different subscripts within row differ significantly at $(\mathrm{P}<0.05)$ level

Table. 2 Lipid peroxidation $(\mu \mathrm{mol} / \mathrm{ml})$ in different groups at various stages of cryopreservation in Gir bulls semen (Mean \pm SE)

\begin{tabular}{|c|c|c|c|}
\hline \multirow[t]{2}{*}{ Groups $(n=8)$} & \multicolumn{3}{|c|}{ Stages of cryopreservation } \\
\hline & $\begin{array}{l}\text { Pre- freeze Stage } \\
\text { (PFS) at } 4^{0} \mathrm{C}\end{array}$ & $\begin{array}{c}\text { Post-Thaw Stage } \\
\text { (PTS) at } 37^{\circ} \mathrm{C}\end{array}$ & Overall Mean \\
\hline Taurine $25 \mathrm{mM}$ & $36.33 \pm 0.76_{a}^{A}$ & $24.53 \pm 0.63^{A}{ }_{b}$ & $30.43 \pm 1.59$ \\
\hline Taurine $50 \mathrm{mM}$ & $30.74 \pm 0.55^{\mathrm{B}}{ }_{\mathrm{a}}$ & $15.95 \pm 0.74^{\mathrm{B}}{ }_{\mathrm{b}}$ & $22.10 \pm 2.06$ \\
\hline Taurine $75 \mathrm{mM}$ & $37.60 \pm 0.63_{a}^{\mathrm{A}}$ & $28.48 \pm 0.55^{\mathrm{C}}{ }_{\mathrm{b}}$ & $33.08 \pm 1.25$ \\
\hline Control & $38.57 \pm 0.70_{a}^{A}$ & $28.07 \pm 1.26^{C}{ }_{b}$ & $33.32 \pm 1.52$ \\
\hline
\end{tabular}

Means with different superscripts within column and Means with different subscriptswithin raw differ significantly $(\mathrm{P}<0.05)$.

Table.3 Glutathione reductase (U/L) in different groups at various stages of cryopreservation in Gir bulls semen (Mean \pm SE)

\begin{tabular}{|c|c|c|c|}
\hline \multirow[t]{2}{*}{ Groups $(\mathrm{n}=8)$} & \multicolumn{3}{|c|}{ Stages of cryopreservation } \\
\hline & $\begin{array}{l}\text { Pre- freeze Stage } \\
\text { (PFS) at } 4^{0} \mathrm{C}\end{array}$ & $\begin{array}{c}\text { Post-Thaw Stage (PTS) } \\
\text { at } 37^{\circ} \mathrm{C}\end{array}$ & Overall Mean \\
\hline Taurine $25 \mathrm{mM}$ & $49.77 \pm 0.72_{a}^{A}$ & $62.91 \pm 0.73_{\mathrm{b}}^{\mathrm{A}}$ & $56.34 \pm 1.76$ \\
\hline Taurine50mM & $64.76 \pm 0.78^{\mathrm{B}}{ }_{\mathrm{a}}$ & $80.25 \pm 0.85^{\mathrm{B}}{ }_{\mathrm{b}}$ & $72.50 \pm 3.09$ \\
\hline Taurinr75mM & $48.39 \pm 0.78_{a}^{\mathrm{A}}$ & $59.94 \pm 0.91^{\mathrm{A}} \mathrm{b}$ & $54.17 \pm 1.60$ \\
\hline Control & $47.29 \pm 0.56^{A}{ }_{a}$ & $59.20 \pm 0.76_{b}^{A}$ & $53.24 \pm 1.60$ \\
\hline
\end{tabular}

Means with different superscripts within column and Means with different subscripts within raw differ significantly $(\mathrm{P}<0.05)$ 
During preservation or cryopreservation, the semen is exposed to cold shock at atmospheric oxygen which in turn increases the susceptibility to lipid peroxidation due to higher production of reactive oxygen species (Perumal et al., 2009).

The free radicals are known to be involved in lipid peroxidation as well as DNA and sperm membrane damages which may lead to decreased sperm motility or cell death. Therefore, in the present study addition of Taurine in semen might be a beneficial factor in avoiding the process of damage and reduce generation of ROS which would otherwise have negatively affected the spermatozoa (Chiller et al., 2012).

\section{Glutathione reductase (GR)}

The mean glutathione reductase (GR) values in for Pre freeze stage and post thaw stage were $49.77 \pm 0.72$ and $62.91 \pm 0.73 \mathrm{U} / \mathrm{L}$ in 25 $\mathrm{mM}$ Taurine group; $64.76 \pm 0.78$ and $80.25 \pm$ $0.85 \mathrm{U} / \mathrm{L}$ in $50 \mathrm{mM}$ Taurine group; $48.39 \pm$ 0.78 and $59.94 \pm 0.91 \mathrm{U} / \mathrm{L}$ in $75 \mathrm{mM}$ Taurine group and $47.29 \pm 0.56$ and $59.20 \pm 0.76 \mathrm{U} / \mathrm{L}$ in control group at pre-freeze and post-thaw stages of cryopreservation, respectively.

The mean glutathione reductase (GR) value in 50 mMTaurine group was significantly $(\mathrm{P}<0.05)$ higher at pre-freeze and post-thaw stages of cryopreservation as compared to that of the $25 \mathrm{mM}$ Taurine, $75 \mathrm{mM}$ Taurine and control groups.

Glutathione reductase (GR) values was found to be significantly $(\mathrm{P}<0.05)$ lower in all the groups at pre-freeze stage as compared postthaw stage of cryopreservation (Table 3 ).

These findings are in accordance with Perumal et al., (2013) who have reported that the addition of $50 \mathrm{mM}$ Taurine resulted in significant increase in Glutathion reductase
(GR) level but for the liquid storage $\left(5^{\circ} \mathrm{C}\right)$ of Mithun bull (Bos frontalis) Semen.

However, Serpil et al., (2009) have reported a significant decrease in Glutathion reductase (GR) level at $2 \mathrm{mM}$ Taurine concentration in bull. Whereas, a non-significant effect of Taurine on Glutathione reductase (GR) levels in ram (Bucak et al., 2007) has been reported.

The GR has a sustained ability in the maintenance of sperm membrane integrity and individual motility. So, higher the GR in the semen might be a factor in making the sperm membrane more resistant to the spontaneous lipid peroxidation that destroys the structure of the lipid matrix and is associated with the loss of motility (Perumal et al., 2009).

Scavenging of the free radicals by Taurine, thereby alleviating GR consumption by the enzymatic antioxidant defenses (Huxtable, 1992) might be implicated in higher GR levels as observed in the present study or it may be due to its ability to maintain the antioxidant system and thereby increasing the level of the GR.(Bucak et al., 2007).

In conclusions, The Malondialdehyde (MDA) level of neat semen of Gir bull which differd significantly between bulls. Whereas Glutathione reductase (GR) level of neat semen of did not differ significantly between bulls. Taurine $(50 \mathrm{mM})$ as a semen additive when added to andromed extender, controls the oxidative stress as indicated by an increase in glutathione reductase and a decline in melondialdehyde (MDA) level at all the stages of cryopreservation in Gir bull semen addition of $50 \mathrm{mM}$ Taurine as an additive in the and romed extender for cryopreservation of semen is most appropriate concentration in view to preserve and improve the semen quality in Gir bull semen. 


\section{References}

Agarwal, A., Makker, K. and Sharma, R. (2008). Clinical relevance of oxidative stress in male factor infertility: an update. American Journal of Reproductive Immunology. 59(1):211.

Aisen, E. G., Medina, V. H. and Venturino, A. (2002). Cryopreservation and postthawed fertility of ram semen frozen in different trehalose concentrations. Theriogenology. 57 (7):1801-1808.

Alvarez, J. G., Touchstone, L., Blasco and Storey, B. T. (1987). Spontaneous lipid peroxidation and production of hydrogen peroxide and superoxide in human spermatozoa: superoxide dismutase as a major enzyme protectant against oxygen toxicity. Journal of Andrology. 23: 338-348.

Atessahin, A., Bucak, M.N., Tuncer, P.B. and Kizil, M. (2008). Effects of antioxidant additives on microscopic and oxidative parameters of Angora goat semen following the freezethawing process. Small Ruminant Research. 77: 38-44.

Bailey, J. L., Bilodeau, J. and Cormier, N. (2000). Semen cryopreservation in domestic animals: a damaging and capacitating phenomenon. $J$. of Andrology. 21 (1): 1-7.

Bansal, A. K. and Bilaspuri, G. S. (2011). Impacts of oxidative stress and antioxidants on semen function. Veterinary Medicine International. 7 pages.686137

Baran, A., Demir, K. and Sahin, B. E. (2009). Short-term chilled storage of cat semen extended with and without taurine containing milk extenders. Journal of Animal and Veterinary Advances. 8 (7):1367-1371.

Bucak, M. N. and Tekin, N. (2007). Protective effect of taurine, glutathione and trehalose on the liquid storage of ram semen. Small Ruminant Research. 73(1-3):103-108.

Bucak, M. N. and Tekin, N. (2007). Protective effect of taurine, glutathione and trehalose on the liquid storage of ram semen. Small Ruminant Research. 73(1-3):103-108.

Bucak, M. N., Sariözkan, S. and Tuncer, P. B. (2010). The effect of antioxidants on post-thawed Angora goat (Capra hircusancryrensis) sperm parameters, lipid peroxidation and antioxidant activities. Small Ruminant Research.89(1):24-30.

Chhillar, S., Singh, V. K., Kumar, R. and Atreja S. K. (2012). Effects of Taurine or Trehalose supplementation on functional competence of cryopreserved Karan Fries semen. Anim. Reprod. Sci. 135(1-4):1-7.

Du Plessis, S. S., Makker, K., Desai, N. R. and Agarwal, A. (2008). Impact of oxidative stress on IVF. Expert Review of Obstetrics and Gynecology. 3(4):539-554.

Huxtable, R. J. (1992). Physiological actions of taurine. Physiol. Rev. 72 (1): 101163.

Maxwell, W. M. C. and Watson, P. F. (1996). Recent progress in the preservation of ram semen. Animal Reproduction Science. 42(1-4):55-65.

Perumal, P., Barik, A. K., Mohanty, D. N., Das, R. K. and Mishra, P. C. (2009). Seminal characteristics of Jersey crossbred bulls. In. Proc. $X X V^{\text {th }}$ annual convention of the Indian Society for Study of Animal Reproduction and International Symposium. p. 196.

Perumal, P., Selvaraju, S. and Selvakumar, S. (2011). Effect of pre-freeze addition of cysteine hydrochloride and reduced glutathione in semen of crossbred jersey bulls on sperm parameters and conception rates. Reproduction in 
Domestic Animals. 46(4):636-641

Perumal, P., Vupru, K. and Rajkhowa, C. (2013). Effect of Addition of Taurine on the Liquid Storage $(5 \circ \mathrm{C})$ of Mithun (Bos frontalis) Semen. Veterinary Medicine International. Article ID 165348, 7 pages

Serpil, S., Bucak, M. N., Tuncer, P. B., Ulutas, P. A. and Bilgen, A. (2009). The influence of cysteine and taurine on microscopic-oxidative stress parameters and fertilizing ability of bull semen following cryopreservation. Cryobiology. 58: 134-138.

Shaikh, K. Q. (2014). Effect of trehalose on quality of cryopreserved banaskankrej bull semen. $M$. V. Sc. Thesis Submitted to SDAU, Dantiwada
(Gujarat).

Sikka, S. C., Rajasekaran, M. and Hellstrom, W. J. G. (1995). Role of oxidative stress and antioxidants in male infertility. Journal of Andrology. 16(6):464-468.

Sinha, M. P., Sinha, A. K., Sinha, B. K. and Prasad, P. I. (1996). The effect of glutathione on motility, enzyme leakage and fertility of frozen goat semen.Theriogenology. 41(3):237243.

Uysal, O., Bucak, M. N., Yavas, I., Varish, O. and Safa, G. I. (2005). Evaluation of ram sperm frozen with various taurine concentrations. Indian Veterinary Journal. 82(10):1059-1061.

\section{How to cite this article:}

Chikhaliya, P.S., A.R. Ahlawat, V.K. Singh, H.P. Vijyeta, M.D. Odedra and Vala, K.B. 2018. Effect of Different Concentrations of Taurine on Certain Biochemical Parameters During Cryopreservation of Gir Bull Semen. Int.J.Curr.Microbiol.App.Sci. 7(07): 1441-1447. doi: https://doi.org/10.20546/ijcmas.2018.707.171 